\title{
A relevância filosófica do conceito de Neutro de Roland Barthes
}

\section{La relevancia filosófica del concepto de Neutro de Roland Barthes}

\section{The philosophical relevance of Roland Barthes' concept of Neutral}

\author{
Eduardo Garralaga Melgar Junior ${ }^{1}$
}

\begin{abstract}
Almir Sodré Bastos ${ }^{2}$
\section{Resumo}

Este artigo pretende destacar a influência e a relevância filosófica do conceito de Neutro, do intelectual francês Roland Barthes. O Neutro corresponde a tudo que burla o paradigma da oposição binária da criação de sentido, portanto, ele é uma "terceira via". Visto que tal conceito não se deixa apreender de forma dogmática e sistemática, o autor utilizou vinte e três figuras a fim de mostrar as possíveis "encarnações" do Neutro: cada uma dessas figuras é, ao mesmo tempo, busca e "mostração" do mesmo. Foram abordadas neste estudo apenas duas delas para não torná-lo demasiadamente extenso. O caráter filosófico do Neutro está intimamente ligado ao ceticismo do grego Pírron, e, em última instância, visa a uma ética, pois conduz a uma "felicidade".
\end{abstract}

Palavras-chave: Barthes; Neutro; Terceira via; Ceticismo; Ética.

\section{Resumen}

Este artículo busca destacar la influencia y la relevancia filosófica del concepto de Neutro, del intelectual francés Roland Barthes. Lo Neutro corresponde a todo que burla el paradigma de la oposición binaria de la creación de sentido, por lo tanto, él es uma "tercera vía". Dado que dicho concepto no se deja aprehender de forma dogmática y sistemática, el autor utilizó veintitrés figuras para mostrar las posibles "encarnaciones" del Neutro: cada una de esas figuras es, al mismo tiempo, búsqueda y "muestra" del mismo. Se abordaron en este estudio sólo dos de ellas para no hacerlo demasiado extenso. El carácter filosófico del Neutro está íntimamente ligado al escepticismo del griego Pírrón, y, en última instancia, apunta a una ética, pues conduce a una "felicidad".

Palabras-llave: Barthes; Neutro; Tercera via; Escepticismo; Ética.

\begin{abstract}
This paper aims to highlight the influence and the philosophical relevance of the concept of Neutral, by the French intellectual Roland Barthes. Neutral matches everything that dodges the paradigm of binary opposition of the creation of meaning, so it is a "third way". Since this concept is not apprehended systematically or dogmatically, the author used twenty-three figures to show Neutral's possible "incarnations": each of these figures are at the same time, search and showing of it. Only two of them were addressed in this study so as not to make it too long.The philosophical nature of the Neutral is intimately connected with the skepticism of the Greek Pirron, and, ultimately, it aims at an ethics, as it leads to "happiness".
\end{abstract}

Key words: Barthes; Neutral; Third way; Skepticism; Ethics.

\footnotetext{
${ }^{1}$ Pós-graduando de Ensino de Filosofia; Universidade Federal de Pelotas; Pelotas, Rio Grande do Sul, Brasil; almir.sodre@gmail.com.

2 Doutorando no Programa de Pós Graduação em Educação em Ciências: Química da Vida e Saúde; Universidade Federal do Rio Grande; Rio Grande, Rio Grande do Sul, Brasil; eduardogmelgar@gmail.com.
} 


\section{Introdução}

Roland Barthes (1915-1980) foi um intelectual francês comumente associado ao estruturalismo, ao pós-estruturalismo, à crítica literária, à semiótica e à antropologia, entre outros campos teóricos. Por este motivo, o autor foi acusado de ser um pensador errático, incerto e inconstante.

Entretanto, após a morte de Roland Barthes e, especialmente, após a publicação de seu curso denominado "O Neutro", ministrado pelo francês entre 1977 e 1978 no Collège de France e publicado em livro em 2002, pôde-se perceber a existência de um fio condutor do pensamento do autor, que se trata justamente do conceito de $\mathrm{Neutro}^{3}$, trabalhado neste curso.

Este artigo tem por objetivo avaliar a relevância filosófica deste conceito. Para tal tarefa, foi realizada uma pesquisa bibliográfica, a qual teve como referência principal a obra “O Neutro - Anotações de aulas e seminários ministrados no Collège de France, 1977-1978”. Este livro é, em verdade, a transcrição dos manuscritos desse curso, o qual foi ministrado por Barthes. Outras referências importantes nesta pesquisa são seus notórios comentadores, como o francês Thomas Clerc e a brasileira Leda Tenório da Motta.

Por certo há muito a ser analisado acerca do conceito de Neutro. Contudo, para este estudo preliminar, não se pretende expor pormenorizadamente todas as influências que levaram Barthes a desenvolvê-lo. Ao invés disso, o foco deste trabalho será a exposição que o próprio intelectual fez acerca deste conceito sui generis durante o curso a ele dedicado. Terão destaque, evidentemente, as influências e as consequências filosóficas do mesmo.

Assim sendo, este artigo será dividido em três seções principais. São elas: "O Neutro", dedicada a apresentar e explicar este conceito; "Figuras do Neutro", que pretende mostrar as "cintilações" do Neutro, expondo algumas figuras onde ele se manifesta; enquanto a terceira seção destaca "O cunho filosófico do Neutro barthesiano", ao avaliar a influência e a relevância filosófica do mesmo, empregando referências tanto de Barthes quanto de alguns comentadores.

Segue, então, este breve estudo acerca da relevância filosófica deste conceito que é o fio condutor do pensamento barthesiano.

\section{O Neutro}

A melhor forma de compreender o conceito de Neutro, essencial no pensamento barthesiano, é recorrendo ao célebre curso ocorrido entre 1977 e 1978, cujas aulas foram anotadas por Thomas Clerc e publicadas na França em 2002. No Brasil, o livro foi publicado

\footnotetext{
${ }^{3}$ Utilizo a grafia em maiúsculo conforme Barthes o fez em seu curso $O$ Neutro.
} 
em 2003 com o título “O Neutro - Anotações de aulas e seminários ministrados no Collège de France, 1977-1978”. Esta será a obra de referência para tornar este conceito mais claro.

Contudo, é fundamental que esteja claro que o Neutro, conforme o francês (2003, p. 25-26), por ser o "não-dogmático", ou ainda a "recusa de dogmatizar", não pode ser exposto de forma dogmática. Por este motivo, o autor utilizou figuras que correspondem a possíveis caminhos de fazer "cintilar" o Neutro. Elas são acontecimentos, sensações e vivências onde o Neutro se manifesta. Entretanto, essas vinte e três figuras do Neutro expostas no curso, não encerram o conceito. Conforme Barthes (2003, p. 22):

Hoje ainda posso ler um livro novo com certos trechos que podem cristalizar-se em torno da noção Neutro [...]: eu leio, a varinha se eleva: tem Neutro aí e, assim, a noção de Neutro modifica-se: ao mesmo tempo me obstino e me modifico.

Entende-se, assim, que a noção de Neutro não é fechada. Ela pode e deve modificar-se sempre que o Neutro se mostrar à percepção. Portanto, segundo Clerc (In: BARTHES, 2003, p. XX), Barthes não pretendeu produzir uma súmula, mas sim um conjunto de direções sobre este conceito. Sua opinião vai ao encontro do que Barthes sinaliza quando diz que o curso não pretende ser um dicionário de definições, mas de cintilações.

\subsection{Definição ou "nomeação"}

A partir das ideias mencionadas, torna-se possível um aprofundamento cauteloso do conceito de Neutro. Logo na primeira aula do curso, Barthes nomeia o Neutro (2003, p. 1617): "Defino o Neutro como aquilo que burla o paradigma, ou melhor, chamo de Neutro tudo o que burla o paradigma. Pois não defino uma palavra; dou nome a uma coisa: reúno sob um nome, que aqui é Neutro". Ou ainda: “Tentação de remover, burlar, evitar o paradigma, suas cominações, suas arrogâncias $\rightarrow$ exonerar o sentido $\rightarrow$ esse campo polimorfo de esquiva do paradigma, do conflito = o Neutro.” (BARTHES, 2003, p. 18). É necessário, então, especificar a quê o autor chama de paradigma:

Paradigma é o quê? É a oposição de dois termos virtuais dos quais atualizo um, para falar, para produzir sentido. [...] O sentido assenta no conflito (escolha de um termo contra o outro), e todo conflito é gerador de sentido: escolher um e rejeitar outro é sempre sacrificar ao sentido, produzir sentido, dá-lo a consumir (BARTHES, 2003, p. 17).

Ainda referindo-se a paradigma, Barthes diz (2003, p. 17): "Segundo a perspectiva saussuriana, à qual, neste ponto, continuo fiel, o paradigma é o móbil do sentido; onde há sentido, há paradigma, e onde há paradigma (oposição), há sentido”. Logo, conforme o autor, o Neutro é o terceiro termo, ou tertium: aquele que desfaz ou anula o binarismo da criação do sentido. Para maior elucidação, pode-se recorrer a um exemplo proposto em aula pelo francês 
(2003, p. 18): "A/B $\rightarrow$ A $+B$ (complexa) e nem A nem B: termo amorfo, neutro (neutralização fonológica, ou grau zero)" - Tal concepção foi influenciada pela linguística estrutural, especialmente Viggo Brøndal. Ou seja, tomando A e B como termos opostos, há duas maneiras de eliminar sua oposição: 1) pela união dos termos $\mathrm{A}$ e $\mathrm{B}(\mathrm{A}+\mathrm{B})$, o que Barthes chama de "operação complexa", ou 2) pela anulação dos mesmos (nem A, nem B), conduzindo propriamente a um termo neutro. Isto remete à etimologia do termo neutro: do latim ne-euter "nem um, nem outro".

Segundo Leda Tenório da Motta (2011, p. 33), o Neutro pode ser definido como: “Utopia de uma linguagem sem marcas, [pois] ele designa o sentido velado, o 'branco' do sentido, [...] uma parada, uma suspensão da linguagem".

Contudo, o Neutro não é um falar para nada dizer, como rotulam alguns críticos do pensamento barthesiano. Quanto a essa acusação, Motta (2011, p. 37) destaca: "Neutro não é o falar para nada dizer, mas um dizer que pode ser incisivo, ainda que em briga com o signo". Tal afirmação vai ao encontro do que Barthes (2003, p. 18-19) disse durante o curso:

Dou uma definição do Neutro que permanece estrutural. Quero dizer com isso que, para mim, o Neutro não remete a 'impressões' de grisalha, de 'neutralidade', de indiferença. O Neutro - meu Neutro - pode remeter a estados intensos, fortes, inauditos. 'Burlar o paradigma' é uma atividade ardente, candente.

Visto que já se estabeleceu um entendimento geral deste conceito sui generis, é importante que se apresente de forma mais detalhada o curso "O Neutro", a fim de possibilitar a compreensão das nuances do mesmo.

\subsection{O curso de $1977-1978$}

O curso teve como objetivo mostrar as "encarnações possíveis do Neutro" - conforme a expressão utilizada por Thomas Clerc (In: BARTHES, 2003, p. XVII). Ele utiliza esta expressão, pois, como anteriormente explicitado, o Neutro não pode ser exposto de forma dogmática justamente porque ele representa o "não-dogmático".

Um fator metodologicamente importante para Barthes foi definir a ordem em que as figuras do Neutro seriam apresentadas. O autor optou por expô-las em ordem aleatória, de forma descontínua e assistemática, pois, segundo ele, isto é uma exigência do próprio Neutro. Ora, se os fragmentos fossem apresentados de acordo com alguma ordem, a exposição, que deveria ser não-dogmática, poderia tornar-se dogmática, infringindo assim o próprio conceito dado pelo autor. De acordo com Barthes, as figuras do Neutro não devem ser articuladas visando um sentido final, organizadas em hierarquia, pois cada figura em particular é busca e "mostração" do Neutro - e "mostração" é diferente de demonstração, como sinaliza Barthes - 
onde o mesmo não se explica nem se define: apenas se descreve. (Cf. BARTHES, 2003, p. 22-23).

Convém, então, citar essas figuras do Neutro referidas por Barthes: a Benevolência; a Fadiga; o Silêncio; a Delicadeza; o Sono; a Afirmação; a Cor; o Adjetivo; Imagens do Neutro; a Cólera; o ativo do Neutro; as Ideosferas; a consciência; a Resposta; os Ritos; o Conflito; a Oscilação; Retirar-se; a Arrogância; o Panorama; Kairós; Wu-wei; e o Andrógino. Bem se vê que a complexidade de abordagem dessas vinte e três figuras tornaria demasiadamente extenso este artigo, que pretende ser breve. Em vista disso, foi necessária a seleção de apenas duas delas para o estudo, a saber, são elas: a Fadiga e o Silêncio. Contudo, a escolha específica dessas duas figuras se justifica pelo fato de elas se prestarem de forma mais direta ao desvelamento do caráter filosófico do Neutro barthesiano. Assim sendo, a próxima seção será dedicada a um olhar direcionado a estas figuras.

\section{Figuras do Neutro}

Antes da exposição das duas figuras do Neutro selecionadas para este artigo, é necessário delinear alguns detalhes acerca das mesmas. Primeiramente, faz-se fundamental esclarecer que essas figuras não são fragmentos do Neutro - para compreendê-lo, não basta juntar fragmentos e montar um quebra-cabeça -, elas são manifestações do Neutro, onde o mesmo "cintila". Barthes (2003, p. 24) disse o seguinte sobre as figuras: "Figura: alusão retórica (= um pedaço delimitado de discurso, localizável porque intitulável) + rosto que tem um 'ar', uma 'expressão': não fragmentos sobre o Neutro, mas no qual, mais vagamente, há Neutro".

Como já foi mencionado, o autor optou por apresentá-las de forma não sistemática, por exigência do próprio Neutro. Isso traz à tona a metodologia que Barthes utilizou para expô-las, pois, para o curso, elas precisavam ser apresentadas em alguma ordem. Visto que o autor não pretendia hierarquizar essas figuras, pois qualquer plano sobre o Neutro violaria a sua essência, o francês recorreu a uma revista de estatística, conforme ele comentou na aula inaugural:

Acaso. Em que ordem pôr as figuras? Pois o sentido não pode 'pegar' [...] já que o Neutro é despegamento do sentido: qualquer 'plano' (agrupamento temático) sobre o Neutro equivaleria fatalmente a opor o Neutro à arrogância, ou seja, a reconstituir um paradigma que o Neutro quer, justamente, burlar: o Neutro se tornaria discursivamente termo de uma antítese: ao se expor, ele consolidaria o sentido que gostaria de dissolver. Portanto, método aleatório de sequência.[...] Título $\rightarrow$ Ordem alfabética $\rightarrow$ Numeração $\rightarrow$ Sorteio: tabela numérica ao acaso: tabela $n^{\circ} 9$ do Institut de statistique de l'université de Paris. Revue de statistique appliquée, 1959, vol. VII, $\mathrm{n}^{\circ}$ 4. Sequência de números de dois algarismos em dez colunas: segui os números por linha no sentido da leitura: acaso puro e simples (BARTHES, 2003, p. 28). 
Dito isto, é possível lançar um olhar atento às figuras da Fadiga e do Silêncio.

\subsection{A Fadiga}

Segundo Barthes, o termo "fadiga" vem de três palavras do latim. São elas Labor, Lassitudo e Fatigatio. Primeiramente, é necessário que se entenda este espectro etimológico para que se compreenda esta figura do Neutro: Labor (trabalho penoso, que empenha todo o corpo), vem de labo (escorregar e cair); Lassitudo (equivalente a "lassitude" em português: cansado, bambo, frouxo) vem de lassus (quem se inclina, quem cai para a frente); Fatigatio (estafar; estar morto; estar morto de cansaço), conforme a expressão francesa faire crever (estourar, rebentar). Barthes empregou uma imagem tópica para ilustrar: a do pneu que estoura e murcha - conforme expressão que Gide (influência de Barthes) utilizou para falar de si mesmo em sua última fase intelectual.

Barthes disse, ainda, que a fadiga não é codificada, não é aceita na sociedade - ele utiliza como exemplo o fato de que o cansaço não é uma desculpa socialmente aceita para cancelar um compromisso, ao passo que uma doença do corpo ou da mente (depressão) o são. Portanto, a fadiga é "sem-lugar": funciona apenas na linguagem do artista ou do intelectual; é insustentável socialmente. A respeito do "sem-lugar" da fadiga, Barthes citou Blanchot: "Não peço que eliminem o cansaço. Peço que me levem para uma região onde seja possível ficar cansado" (BARTHES, 2003, p. 41-42). O francês ainda ressaltou (Ibidem, p. 41) que o cansaço é uma reivindicação do corpo, que exige o direito ao repouso social, exige que sua socialidade descanse por um momento. Eis aí uma face do Neutro.

Para melhor entendimento, Barthes apontou uma situação na qual o cansaço vem à tona: a conversa. Ela cansa porque cobra uma posição e, por este motivo, há "dificuldade de flutuar, de mudar de lugar. (No entanto, flutuar, ou seja, habitar um espaço sem se fixar num lugar = atitude mais repousante do corpo: banho, barco)" (BARTHES, 2003, p. 43). Por isso, ainda segundo o francês (2003, p. 42), a conversa de desconhecidos é menos cansativa, porque não exige uma tomada de posição.

Barthes ainda sustenta que a fadiga pode levar à criação. Como exemplo ele destaca o cético grego Pírron, que, como veremos adiante, cansado da oposição entre a dialética de Platão e o palavrório dos sofistas, preferiu abster-se de tomar uma posição, criando, a partir de sua atitude, uma nova forma de pensar o mundo. Portanto, disse Barthes (2003, p. 48), “o direito ao cansaço [...] faz então parte do novo: as coisas novas nascem da canseira". Sendo assim, percebe-se que há necessidade de um afastamento das opções, um cansaço, pra que haja, efetivamente, a criação e para que se possa escapar das imposições do paradigma. 


\subsection{O Silêncio}

Barthes iniciou a exposição desta figura dizendo que na linguagem atual, calar-se e silenciar são sinônimos. Entretanto, no latim havia uma nuance interessante, duas formas de silêncio: tacere (silêncio verbal) e silere (tranqüilidade, ausência de movimento, "silêncio" da natureza), conforme disse Barthes (2003, p. 50): “Tacere, como silêncio da fala, opõe-se a silere, como silêncio da natureza ou de divindade, depois, último avatar, em francês as duas se igualam, tornam-se sinônimos"4. Contudo, na linguagem contemporânea, tacere leva vantagem: quando se fala em silêncio, quase sempre se refere à fala. A natureza, como diz o francês, é de alguma forma sacrificada à fala.

O autor ainda destacou que desde a antiguidade, na Grécia, havia uma demanda pelo direito à palavra, pelo direito de falar em assembléia - existe, inclusive, um nome para isto: isegoria. No entanto, o Neutro busca o direito ao silêncio, direito de calar-se e de não ouvir. Assim resumiu Barthes (2003, p. 52): "Neutro = postulação de um direito a calar-se - de uma possibilidade de calar-se".

Tal possibilidade de calar-se é, conforme o autor, uma forma de frustrar a fala, suas opressões e intimidações. Ou seja, é uma forma de burlar o paradigma, visto que no silêncio, a princípio, não há escolha por algum dos termos que se opõe no já referido binarismo da criação de sentido. Barthes (2003, p. 53) frisou, ainda, que "o silêncio não é um signo no sentido próprio, não remete a um significado: está lá como tacet de uma partitura". Entretanto, ele pode representar um posicionamento, pois nem sempre o silêncio é recebido como tal - a isso o francês chama de "semiologia da moral mundana". Logo, como indicou Barthes (2003, p. 54), "Na 'semiologia' da moral mundana, o silêncio tem de fato uma substância 'faladeira' ou 'falante': ele é sempre o implícito".

Contudo, é importante destacar que não é este silêncio "falante" que representa o Neutro: existe também o que Barthes chama de "silêncio do cético", intimamente ligado ao ceticismo de Pírron ${ }^{5}$ : conforme o filósofo grego, tal silêncio é deduzido do fato de ser impossível discernir se uma determinada afirmação corresponde à verdade. Este silêncio diz respeito não a um calar da boca, mas sim da razão. O que se recusa é a fala sistemática, dogmática (Cf. BARTHES, 2003, p. 56-57). Portanto, é este "silêncio do cético" que corresponde a uma encarnação do Neutro.

\footnotetext{
${ }^{4} \mathrm{O}$ mesmo pode ser dito em relação a esta palavra na língua portuguesa.

${ }^{5}$ Tal relação será mais detalhada na seção posterior.
} 
Ambas as figuras aqui abordadas são de alguma forma relevantes no que tange ao caráter filosófico do Neutro barthesiano, como será mostrado a seguir.

\section{O cunho filosófico do Neutro barthesiano}

Após esta exposição, algumas considerações tornam-se possíveis. Poder-se-ia dizer que Barthes é um filósofo? Muitos afirmam que sim. É o caso de Madeleine Renouard, professora na Universidade de Londres, que no ano de 2004 organizou, nesta mesma universidade, um colóquio dedicado ao francês onde ele era visto como tal. Este colóquio contou com falas de Eric Marty e do poeta Yves Jouan. Também concorda com esta opinião o filósofo e linguista Jean-Claude Milner, que em 2003 publicou Le pás philosophique de Roland Barthes onde ele destaca que Barthes escolhe a filosofia. Milner chega a essa conclusão partindo da observação dos termos utilizados por Barthes, notadamente grafados com letra maiúscula e precedidos por artigo definido - por exemplo, o Neutro -, afirmando que isto consiste em uma atividade que procura tirar as palavras de seu uso comum, dizendo, dessa forma, que Barthes as marca filosoficamente (Cf. Motta, 2011, p. 41). Outro filósofo que partilha da mesma ideia é François Dosse, que associa a última fase de Barthes com a desconstrução de Jacques Derrida. A comparação é justa, pois a ação do Neutro é desconstrutora. Entretanto, ao afirmar isso, Dosse não leva em conta que, antes de Derrida apresentar sua desconstrução, Barthes já havia publicado $O$ grau zero da escrita, onde o Neutro já estava esboçado. Logo, o Neutro é anterior à desconstrução.

Mas, enfim, qual seria o caráter filosófico do pensamento barthesiano? Em relação a esse questionamento, Leda Tenório da Motta (2011, p. 45) se posiciona da seguinte forma: "se porventura de filosofia se trata, o que o Neutro barthesiano subscreve, em plena contemporaneidade, é aquela filosofia que passa ao largo da filosofia. Aquela filosofia cujo único alvo é entreter a dúvida: o ceticismo". A brasileira faz essa relação partindo da observação da influência de Montaigne ${ }^{6}$ em Barthes cujas "Notas sobre o Diário de André Gide”, avalia que Montaigne é “o homem por excelência”. Motta entende que essa afirmação permite que se pense que o homem por excelência é o cético, visto que Montaigne decidiu, subitamente, aos 42 anos de idade, manter-se até o fim de sua vida à distância de toda tomada de posição a favor ou contra qualquer idéia (Cf. MOTTA, 2011, p. 48-49). Ainda, de acordo com Barthes (2003, p. 371), para assinalar essa atitude distanciada, em 1576 ele mandou fundir uma medalha onde em uma das faces se via suas armas e, na outra, sua idade, uma balança em posição de equilíbrio e um lema: “Abstenho-me”. Este é justamente o lema do

\footnotetext{
${ }^{6}$ Montaigne: filósofo cético francês, considerado o inventor do ensaio pessoal.
} 
cético grego Pírron. Portanto, por influência de Montaigne, Barthes se faz a si mesmo tributário de Pírron, como ele mesmo deu a entender quando disse: "Ressaltei várias vezes [...] a relação de tentação existente entre o pirronismo e o Neutro" (BARTHES, 2003, p. 371).

Por conseguinte, para melhor compreensão da relevância filosófica do Neutro, é fundamental observar atentamente sua relação com o ceticismo de Pírron.

\subsection{A dimensão cética do Neutro}

O Neutro barthesiano apresenta afinidades com o ceticismo de Pírron, conforme o próprio autor destacou na aula de 4 de março de 1978: “Uma das 'orientações' filosóficas que mais afinidade tem com o Neutro, a saber, o pirronismo...” (BARTHES, 2003, p. 80-81). Logo, para a apreensão de tal relação é essencial apontar alguns detalhes sobre este filósofo grego.

Assim como Sócrates, Pírron nada escreveu. Deste modo, tudo o que se sabe sobre ele e sua filosofia é procedente dos escritos de seus discípulos. O mais notório dentre eles foi Tímon, cujo testemunho sobre seu mestre chegou aos nossos dias graças aos fragmentos de um livro de Aristócles de Messena, obra esta dedicada à história da filosofia. Assim Aristócles descreveu o pensamento do cético:

'Pírron de Elida (...) não deixou nada escrito, mas seu discípulo Tímon afirma que aquele que quer ser feliz deve atentar para estas três coisas: 1) em primeiro lugar, como são as coisas, por natureza; 2) em segundo lugar, qual deve ser nossa disposição em relação a elas; 3) finalmente, o que nos ocorrerá se nos comportarmos assim. Tímon diz que Pírron mostra que as coisas: 1) São igualmente sem diferença, sem estabilidade, indiscriminadas. 2) não é, pois, necessário ter fé nelas, mas sim permanecer sem opiniões, sem inclinações, sem agitação, dizendo a respeito de tudo 'não é mais do que não é', 'é e não é' ou 'nem é, nem não é'. 3) Aos que se encontrarem nessa disposição, Tímon diz que derivará em primeiro lugar a apatia, depois a imperturbabilidade' (REALE; ANTISERI, 2003, p. 302).

De acordo com Barthes, tal pensamento de Pírron originou-se de uma Fadiga: o grego cansou-se do paradigma filosófico de sua época (dialética platônica versus retórica sofista), levando-o a deduzir um Silêncio: ele absteve-se da tomada de posicionamento a favor ou contra qualquer ideia, visto que, para ele, não havia meios de se escolher a melhor opinião. Esta atitude corresponde a uma "encarnação" do Neutro, conforme disse o intelectual francês (2003, p. 48): "Desse modo, assumindo seu cansaço - a fala dos outros como algo excessivo, oprimente -, [...] ele [Pírron] criou o Neutro".

Entretanto, o silêncio do cético não é uma atitude de covardia intelectual, como destacou Barthes quando falou sobre a figura do Silêncio. A respeito disto, ele citou o cético neo pirronista Sextus Empiricus: 
Quando um cético adota a atitude silenciosa, não está buscando na dúvida um refúgio confortável, ou um meio de evitar o erro. Ao contrário, só está descrevendo o estado de equilíbrio de sua alma diante de representações incertas e submetidas a forças igualmente contrárias (BARTHES, 2003, p. 57).

Barthes ressalta, ainda, que se deve ter a clareza de que tal silêncio não é o verbal, mas sim o silêncio da razão. O que se recusa é a fala sistemática, dogmática, por isso Pírron não escreveu sobre o ceticismo. Contudo, o silêncio também pode ser sistemático, quando nele está implícita uma tomada de posição. A grande aproximação entre o pirroniano e o Neutro, segundo o autor, é que "o jogo da fala e do silêncio não seja sistemático: que, para contrariar a fala dogmática, não se produza um silêncio também dogmático" (BARTHES, 2003, p. 62).

Com efeito, o autor separa Pírron do ceticismo dos seus discípulos, visto que a partir do momento em que este ceticismo tenta impor valores de verdade, passa a ser também dogmático, por isso ele fala em "ceticismo pirroniano" e não em "pirronismo". O francês deixou essa separação bem clara quando disse: "Não confundir Pírron e o ceticismo dogmático" (BARTHES, 2003, p. 61). Assim sendo, tanto o Neutro quanto o ceticismo de Pírron tratam da epokhé, conforme definiu Barthes (BARTHES, 2003, p. 412): "Epokhé: noção fundamental do ceticismo grego = suspensão (de juízo) [...] não da impressão".

Percebe-se, portanto, que, assim como o Neutro, o ceticismo pirroniano é a linha do meio. Em comum a ambos está um cansaço em relação ao paradigma e um desejo de burlar o jogo por meio do silêncio. Outra aproximação importantíssima: em última instância, eles conduzem a uma ética.

\subsection{A dimensão ética do Neutro}

A fim de esclarecimento dessa ética do Neutro, mencionada anteriormente, convém observar novamente o que Tímon dizia a respeito de Pírron: "Aos que se encontrarem nessa disposição [a de permanecer sem inclinações a respeito das supostas verdades], [...] derivará em primeiro lugar a apatia, depois a imperturbabilidade" (REALE; ANTISERI, 2003, p. 302). Ora, se a apatia e a imperturbabilidade derivam da atitude cética, da epokhé, trata-se, então, de uma dimensão ética, pois, como disse Barthes (2003, p. 413): "Epokhé [...] visa a uma 'felicidade', a um 'ajuste'”. O autor também sinalizou o caráter ético do ceticismo - e, por consequência, do Neutro - ao afirmar, sobre o silêncio pirroniano: "trata-se então de um silêncio psicológico (diz respeito à 'alma'), lógico (deduzido da contradição das 'verdades') e ético (visa a obter repouso, ataraxia)" (BARTHES, 2003, p. 57).

Em concordância acerca da dimensão ética da epokhé, a filósofa brasileira Marilena Chauí (2010, p. 58-59) endossa: 
[A suspensão do juízo] não se refere apenas à ontologia e ao conhecimento, mas também à ética. Nos dois primeiros casos, ela conduz ao silêncio [...], no terceiro à impassibilidade ou ausência de paixão [...] e à quietude ou serenidade ou tranqüilidade da alma. [...] Em outras palavras, esta canônica não se refere apenas ao ser e ao não ser, mas também ao bom e ao mau.

Logo, a ética do Neutro barthesiano parece ser sua conseqüência mais relevante. O próprio autor admitiu na primeira aula do curso "O Neutro": "O que procuro, na preparação do curso, é uma introdução ao viver, um guia de vida (projeto ético)" (BARTHES, 2003, p. 27).

Portanto, o cunho filosófico do Neutro barthesiano está intimamente ligado ao ceticismo pirroniano, visto que ambos nascem da Fadiga, operam por meio do Silêncio e conduzem a uma dimensão ética.

\section{Considerações finais}

Neste artigo procurou-se avaliar a relevância do conceito de Neutro, de Roland Barthes, evidenciando as influências e consequências filosóficas do mesmo.

O Neutro corresponde a tudo o que burla o paradigma da criação de sentido - a oposição binária entre dois termos. Ele é a terceira via; uma alternativa de não escolha a um ou outro desses termos em oposição. Uma vez que o Neutro é o "não-dogmático" e visto que ele não se deixa apreender em um conceito dogmático, o autor utilizou vinte e três figuras a fim de mostrar as possíveis "encarnações" do Neutro; cada figura é busca e "mostração" do Neutro - termo utilizado por Barthes. A fim de não tornar este artigo demasiadamente extenso, foram selecionadas duas dessas figuras para estudo mais minucioso: foram elas "a Fadiga" e "o Silêncio". A escolha específica destas figuras deve-se ao fato de as mesmas se prestarem de forma mais direta ao desvelamento do cunho filosófico do Neutro barthesiano. Quanto a este tema, mostrou-se que o Neutro apresenta forte afinidade com o ceticismo de Pírron, pois ambos se traduzem numa recusa à tomada de posição contra ou a favor qualquer termo em oposição. Tal atitude de suspensão do juízo conduz, em última instância, a uma dimensão ética, pois visa a uma "felicidade", a um "ajuste" - como diz Barthes. Assim sendo, o caráter filosófico do Neutro barthesiano é cético e ético.

Portanto, o estudo do Neutro barthesiano parece ser de grande importância para futuros estudos, especialmente na área da filosofia, justamente pelo seu potencial transformador e, principalmente, porque em nos tempos atuais, cada vez mais conflituosos e perturbadores, faz-se necessário um repensar das ações cotidianas e políticas, tendo em vista uma vida melhor. O próprio intelectual francês (2003. p. 30) encoraja os estudos sobre o 
Neutro, quando diz: "A descrição tópica, exaustiva, final desse desejo de Neutro não me cabe: é meu enigma, ou seja, o que de mim só pode ser visto pelos outros". Assim, este trabalho é o resultado da decisão de tomar este desafio. Por certo este estudo preliminar não dá conta de se aprofundar pormenorizadamente em todas as nuances do Neutro, entretanto, ele é o ponto de partida de futuras pesquisas, que darão continuidade às pesquisas acerca do Neutro, esta fascinante forma de pensar e de viver.

\section{Referências}

BARTHES, Roland. O Neutro - Anotações de aula e seminários ministrados no Collège de France, 1977-1978. Texto estabelecido, anotado e apresentado por Thomas Clerc. Tradução de Ivone Castilho Benedetti. São Paulo: Martins Fontes, 2003.

CHAUI, Marilena. Introdução à História da Filosofia - As Escolas Helenísticas, v. 2. São Paulo: Companhia das Letas, 2010.

CLERC, Thomas. Prefácio. In: BARTHES, Roland. O Neutro - Anotações de aula e seminários ministrados no Collège de France, 1977-1978. Texto estabelecido, anotado e apresentado por Thomas Clerc. Tradução de Ivone Castilho Benedetti. São Paulo: Martins Fontes, 2003.

MOTTA, Leda Tenório da. Roland Barthes: uma biografia intelectual. São Paulo: Iluminuras, 2011.

REALE, Giovanni. ANTISERI, Dario. História da Filosofia - Filosofia Pagã Antiga, v. 1. Tradução de Ivo Storniolo. São Paulo: Paulus, 2003. 